\title{
Testing Microstructure Theory on Karachi Stock Exchange
}

\author{
Nadeem Nazir ${ }^{1 *}$, Hamad Raza ${ }^{2}$ \\ ${ }^{1}$ Government College University, Faisalabad, Pakistan \\ ${ }^{2}$ Universiti Teknologi Malaysia, Malaysia \\ Nadeemnazir1@gmail.com
}

\begin{abstract}
We are analyzing the various measures of liquidity of Karachi Stock Exchange Market on the basis of microstructure theory. The concept of microstructure is focusing on the difference between the supply price and demand price of securities in any market. In other words, the price formation of the bid-ask spread is based on the supply and demand prices. Empirical studies conducted by different researchers have made a lot of contribution in this regards. As they concluded that bid-ask spread is constituted on the basis of different theories of liquidity. Historical background of microstructure literature shows that bid-ask spread constitutes the fundamental measure of the liquidity in any market. As a result of this it contributes to identify the best structure of stock market. There may be other admitted measures of liquidity. In the opinion of different researchers the internationally accepted measures of liquidity formation in any market include the Lambda, Turnover of the concerned security, Depth of that market, The Cost of Trip, Trade of security, etc. And they work as strong indicators of liquidity. Our study is a contribution to the literature as we try to explore those correlated variables that can be significantly and sequentially change. And they are serving a measure of the individual's securities that are already traded in Karachi Stock Exchange Market. These admitted variables of our study are trading volumes of securities, number of transactions in the market, security return, volatility of securities prices, arrival of new information etc. we take a sample of 350 quoted securities in Karachi Stock Exchange Market, from 1990-2015. As far as result is concerned, depth showed a negative correlation with all spread measures in the Karachi Stock Exchange Market. But at the same time, perfect positive correlations are shown between spread measures in the analysis. It is a perfect proof of existence and validity of these liquidity measures in KSE. The results is evidencing that the arrival of new information, return on investment, volume of traded securities; are contributing a lot to explain significantly the sequential changes in KSE. At the same time various measures of the securities regarding liquidity are proving and confirming the previous researcher's claim. In the end, analysts are in a better position to explain that the arrival of new information from different sources and different groups is functioning as a principal aspect for the variant contributories of liquidness of the Karachi Stock Exchange.
\end{abstract}

Keywords: Ask Spread, KSE, Liquidity Measurement, Theory of Microstructure, Price Information, Liquidity and its Commonality

\section{Introduction}

This research is reviewing the empirical literature on liquidity and asset pricing model. Detailed scrutiny of literature is evidencing, the liquidity how affecting the security return, and how link is created between these two. Some researchers think that liquidity is a complicated phenomenon and it may be explained as how easily the security is traded in the market. Friction free market is a market created on the basis of Asset Pricing Models (i.e. Option Pricing Model, (MEO), Capital Asset Pricing Model (CAPM) and Arbitrage Pricing Theory (APT). Friction or illiquidity is formed with market microstructure influencing inversely the price and liquidity of the market. Liquidity of market is a guarantee to the investor that he can trade security without delay and without loss. And this liquidity is a best measure of capital market. Liquidity does not bother about the traded volume. Investors are interested in exchange without delay. Various elements of market upon which the liquidity depends are nature of exchange, structure of market and other factors. Demsetz (1968) studied micro market structure and he realized that primary reason is bid ask spread. Other literature studied that transaction cost and market efficiency are also closely related. During its life time whenever any security is traded the buyer/ seller has to incur this transaction cost, brokerage cost, transaction taxes and order processing fee are all exogenous cost and all are causing illiquidity. Similarly they explained "quoted bid ask spread" is also a poor measure of checking of market liquidity. Researchers like Amihud (1989) studied that bid ask and bid trade is only a precise measure of liquidity. Then defect of traditional measures of liquidity friction like transaction cost (like bid ask spread) was studied by Hasbrouck (1993) and he introduced a new measure of liquidity like "trading restrictions". 
Liquidity measure variable used by early researchers like Chordia and Subrahmanyam (2000), are trading volume and security rate rotation. Similarly quoted spread, affective spread and quoted depth were also taken as measures of liquidity by Chordia. Other researchers consider volatility of prices, lambda, CRT (cost of round trip trade) as measures of liquidity. Bagehot (1971) considered the pattern of bid ask spread and trading volume as a measures of liquidity. Eagle and Lange (1997) explained that liquid market is that market where trade can be carried on without any cost. Different researchers still used "bid ask spread" as a measures of liquidity. Cost of completing a small trade is measured rightly by the above said variable (Michael.j. Fleming). Still the researchers are interested in finding out those variables, which can affect the liquidity of the market.

Researchers like Bellalah \& Simon (1999), studied the microstructure of market and literature on liquidity. Brennan (1996) explored inverse relationship between trading value and return. Similarly strong correlation was observed by Chordia and Subrahmanyam (2000) between measure of liquidity (spread depth) and trading value. Few other researchers try to find out the relationship between market liquidity and other variables like quoted tick size, volatility of securities and number of transactions, information, etc. Our study is relating to the determination of measures of factors of microstructure relating to the measure of liquidity in Karachi stock exchange. In this ground extensive literature relating to the liquidity has been explored. Efforts have been made to explore the various determinants of liquidity in Pakistan Stock Exchange Market. We are further trying to determine various variables which determine price quoted traded volume in stock exchange of Pakistan. The rosy face of this research is the presentations of institutional and methodical interest. On the head side of this coin, various theories like bid ask spread theory version and theory version microstructure of the financial market; are determinants of market liquidity and measures of liquidity will be explored on their basis. On the tail side of the coin, new parameters of liquidity measuring like depth of the market and spread is to be explored.

\section{Concept of Market Microstructure Theory in Pakistan}

Price is the reflection of all public information as narrated by Canonical Model of efficient market. Price at market level remains at expected level due to the agent information and due to absence of any ridiculous frictions. Similarly, Asset Pricing Model (MEDAF, MEO, and APT) are all based on the concept of independency of market design, transaction cost and dealers behavior. It is the evidence of existence of the market that is free from frictions. On the other hand, heterogeneity of market information and friction of prices is the subject matter of microstructure theory of market. Various frictions like transaction cost disagreement between dealers are not reflected in the price of market. Demsetz (1968) considered these friction bid ask spread as the subject matter of market microstructure theory. The difference between buyer price (bid) and seller price (ask) is called Bid ask spread. For the purpose of analysis bid ask spread is to be divided into 2 parts (Clyman, 1998). First portion of the bid ask spread is the potential loss indemnity and the second portion will make a difference between inventory holding cost and order processing cost.

How to Explain the Measures of Liquidity in KSE: Liquidity has wide ranging effects on the capital markets. It is hard to explore the concept of liquidity. So Liquidity of an asset means that its transfer to another person without any decrease in prices on immediate basis into dollar value (Keynes, 1930). Two important concepts explained in this definitions include "short-term" and the "without loss price." On the other hand if this definition is practically applied to financial market model, then it is clearly observed that financial market is said to be liquid, if the buyer and seller of securities can get their desired quantity of securities at a fixed price". Literature review regarding liquidity explored the two faces of liquidity, i.e. time and cost. Both these two constituents of liquidity enjoy inverse relationship with each other. Investor is ready to get maximum advantage but time is inversely affecting price of transaction. Patience is required to get this advantage. Liquidity has a complex face where four different dimensions are defined by (Black, 1971) to measures this in market. These include immediacy, depth, fighters and resilience as observed. By immediacy, we consider the hurriness to perform transaction. On the other side depth is the situation where the larger orders can be executed without affecting price in the market. Bid ask spread is the measure of tightness of the market. While resiliency refers to phenomenon i.e. the time of original position after asks and bid schedules are over.

Liquidity in Pakistan Stock Exchange: Pakistan Equity Market has geared another year of stellar, returns 
where over KSE-100 index target of 14,350 points offers an upside of $27 \%$ from current levels. Our primary objective is to analyse the liquidity determinants in Pakistan. There is a scarcity in this field in Pakistan as far as the topic is concerned. Only a few studies so far here have been carried on in Pakistan. So due to this reason and to fill the gap, this topic is selected for our study. Frino (2006) carried on his study "the effects of liquidity on stock return." different researchers in other countries conducted their studies on the topic. In spite of this fact, that a large work done in foreign countries, its true face cannot be seen so far. This research in Pakistan is a source of helping a lot both in academia and practitioners side. Clyman (1998) considered the different factors which are responsible for smooth working and better performance of the capital market anywhere in the world. They are identified as economic actions are grown in country; stability of foreign currency rate is present, reduction in debt service charges, liabilities and loans of the country decrease, deferment and repayment of external loans, and global joint ventures. Clyman (1998) explored that political, legal, and economic factors are affecting stock exchange market and capital market in Pakistan. Historical background shows that KSE is the oldest market in Pakistan. It is emerging in South Asia. Pakistan largest market was established in 18-09-1947 as the first stock exchange after the independence of Pakistan on 14-08-1947. In 1974 LSE (Lahore Stock Exchange) was established and ISE (Islamabad Stock Exchange) was constituted in 1997. Effects of any political instability can be easily seen in stock exchange market in Pakistan (Muneer et al., 2011). In Pakistan SECP is responsible for checking and the smooth working of stock exchange. Terrorism and the law and order situation are now major issues of Pakistan. Recent attack on Pakistani school children (16 December, 2014) has brought all the political forces of Pakistan, the Government of Pakistan, all major religious parties and the civil \& military establishment, on one page. This is helping to improve the country's sluggish economy.

Numerous studies have been conducted on stock market issue and macroeconomics factors in Pakistan. Macroeconomics factors like investment at domestic level, level of income in the country, liquidity of capital market, development and growth at banking segment, capital inflow at private level, and institutional determinants such as law \& order, political risk and bureaucratic quality are the basic elements that determine the basic stock market (Charles Amoy arty, 2008). In Pakistan since (2001-2005) stock market was working very well and it was quite liquid (Frino, 2006). Many well-known global fund managers like Morgan Stanley, Merrill, Lynch, Goldman, Sashes etc. also gained entry in Karachi stock market as global fund manager. Later on in 2005 and 2006 market lost liquidity and declined sharply. Due to negative real interest, high inflation rate further decrease the interest rates due to State bank of Pakistan monetary policy. However, Govt took certain steps to improve liquidity in the market. In Pakistan stock market tightly controlled margin trading system (MTS) was introduced and dealing requirements in the deliverable future market (DFM) were made ultrastringent. Naqvi (the News 2011) explained that Pakistani Stock exchange market is facing two types of problems (Khan et al., 2013).

A- Problem of speculation. B- Problem of liquidity: State Bank of Pakistan is seriously taken certain steps to resolve these problems. SECP (Securities and Exchange Commission of Pakistan) being a frontline regulator of stock exchange and the APEX another regulator is trying to create an environment, where cheating is minimized, the systematic risk is contained and there are check and balance on excessive greed by means fair or foul.

Steps of Liquidity Measurement: The exploration of financial literature by different researchers has explained that a number of measures have been used to determine the liquidity of the market anywhere in the world. The view of microstructure theory has considered different problems in determination of liquidity of market. The precise survey of the Karachi stock market shows that delicacy is required for the liquidity determination which totally depends upon quotations and the market design. Various measures of liquidity determination used in the financial literature may include the spread, liquidity ratio, ratio of rotation of security, Cost of round trip, the volume of trading activities, VNET, market depth, etc. in the Karachi stock exchange market.

Trading Volume explained: In the opinion of Demsetz (1968) "liquidity is measured by trading volume. This is maladjusted, because it disregards perspectives of the concept of liquidity (immediacy, tightness, depth and the resiliency as it is considered previously)." 
Concept of the Liquidity Ratio: Another important researcher Copeland (1983) studied that it is the reporting of the absolute prices variations to the volume traded in the market. For further understanding of this concept we may take it as the measure of liquidity degree of securities in the liquid market.

The concept of Turnover in the market: By Turnover we mean that the phenomenon is used to measure the financial asset liquidity of the market. If we want to calculate "turnover" by a simple formula; we consider it as, it is the sum total of all the securities exchanged there in a deal dividing it by the sum total of the circulating securities in that market at that time. There may the chances of criticism on this measure of market liquidity as it ignores to integrate traits of the phenomenon of liquidity for any further clarification.

The concept of ask-bid spread: In the opinion of different researchers the best measure of the concept of liquidity in market of the world is called as the spread. It is helpful for us if we want to make a difference between the concept of quoted spread and the concept of the effective spread for the purpose of our research. In the opinion of some other researchers, illiquidity may be measured with the help of the spread.

Market and concept of its Depth: Literature explained that "Depth" is treated as the stronger proxy of liquidity measurement in the financial literature. It may be explained as follows, "Depth" is calculated as the number sum total of securities open for offer to "ask" dollar value including the sum total of securities requested and required at "bid" dollar value in the market. Its measurement is made as follows; the quantity of monetary units (dollars depth) or quantity securities exchanged (depth quantity) in any market. Researchers considered that floor-based markets do not offer this feature as it is the special feature of the electronic markets. In the former case many people are treated as the supplier of liquidity but unable to comply with some orders due to its existence in the market.

The concept of Lambda: In the opinion of Kyle (1985), slope of the linear line is measured with help of the lambda. As he observed that to explore the degree of illiquidity of securities there exist direct equality relationships between quantities to be taken in a note orders-book 1 and market prices. We assume that there is the existence of a linear association between the prices in the market and quantities exchanged.

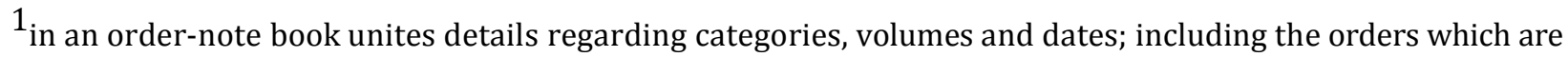
in waiting list waiting relating to the asked price and the prices which are open offer.

The concept of excess VNET buying: Another group of known researchers like Robert and Lange (1997) explored this innovative idea of liquidity measurement in the market. The brighten side of this new variable of market liquidity measurement "VNET" is that it is framed by the extra volu me regarding purchase and sale presence in capital market. As it is also an important source of explaining the shifts in price in the market. We treat market as illiquid, if price of different securities are increasing with a feeble excess buys. And on the other hand the depth of the market is more important if the similar rise in the price is seen with a big excess of buys in that market. This excess VNET is a source of measuring that volume which is available for trading before prior to the adjustment of the prices in the market. If it is appearing that V.NET converge to zero, and then very liquid market will exist.

The concept of CRTRP (the cost of round trip trade): An external measure of market liquidity, i.e. CRTRP is proposed and designed by Paul and George (2000). They consider it as follows "All low values of buyer prices "bid" and those of the high values of seller prices "ask" are respectively: $\operatorname{Pr}-1>\operatorname{Pr}-2>\operatorname{Pr}-3>\ldots .$. and $\operatorname{Pr} 1<\operatorname{Pr} 2<\operatorname{Pr} 3<\ldots$ and so on. Quantities of securities offered and asked are represented by the vector: Qt $(\ldots$ .Qt-2 Qt-1 Qt-0 Qt0 Qt1 Qt2....)." For further explanation of the new definition of two pointers: I k and I -k that is in relation to the order given by the buyer and the order given by the seller and the value is explained in dollars. This is described as follows

How Different Factors Are Influencing the Liquidity of The Stock Market: In order to increase the confidence of investors, a keen study of all those factors is necessary which determine the liquidity of financial market. These various factors include market design regulators and measurement of investment and also other factors. Previous studies carried on by different researchers explained those factors which serve 
as basis of measuring liquidity (Kyle, 1985; Amihud and Mendelson, 1986; Admati and Pfleiderer, 1988).

Reaction of Insider's Transaction \& Information's: Two types of asymmetric information are available in the market. To check their impact on bid-ask spread, different studies are carried on by the prominent researchers. Goldstein \& Kavajecz (2000) carried on analysis of all occurrences and changes in data at the time of declarations of earnings. In first case, the investors are informed by financial analysis or by the insider's before the announcement. In the second case, asymmetric information is made public. Due to this information flow, investor can get better advantage over the other. Glosten, Lawrence and Milgrom, (1985) explored the history of bid-ask spread on quarter basis outcome declared on the study of 25 securities quoted on the OTCNTR (over the counter). The sample of 25 securities comprised of period from 1973-76. But the insignificant results are shown on the change of the bid-ask spread around the date of announcement. Ho (1981) explored the history of the "quoted depth" and "quoted spread" (it is assumed that it is a "Proxy" of measurement of liquid position of the market) on 80 interims of a 30 minutes where earnings declaration in the market. Market liquidity was deteriorated as results of entry of insiders. Annaïck (2001) studied quoted spread evolution of following insider's transactions. Resultantly, criminal transaction was completed by insiders as the transaction was enlarged on days: where quotations session was over the normal level was recovered.

Reaction of Returns and Liquidity Consideration in the Market: Some researchers explained that return may be influenced by the measures of liquidity. As transaction cost is high in less liquid market hence investor must be compensated so expected returns is a decreasing function of liquidity (Amihud and Mendelson, 1986). He further explored that investment decision does not depend only on specific risk but also to their liquidity risk. Portfolio techniques help the investor to diversify his investment to reduce risk. Amihud and Mendelson (1986) further studied that liquidity has important measurable effect on return. So they tried to asset pricing for the measurement of liquidity on the basis of bid-ask spread available in the market. Their exploration and investigation regarding the predictable return may a strong concave function of ask-bid spread. The strong positive relation was observed during a study on New York Stock Exchange (Amex, ordinary Stock during 1961-80). It is evident from the results that weak liquid investment generates elevated returns for their holders. Similarly, Portfolio choice and investment have certain implications.

Reaction of the Tick Size Liquidity Choice for the Investors: Literature is rich with this topic i.e. Tick size as a measure of liquidity. It is the minimum price changes experienced for quoting and trading stock. Fixation of tick size may be either by price level percentage or by the authorities of market without keeping in view the price. As it is in the form of subsidy paid to liquidity provider hence reduction in tick size will naturally a source of reduction in liquidity (Harris 1994). Market liquidity provision is decreased due to reduction in tick size as liquidity providers reduce their intervention into market. Bid-ask spread is positively related to tick size as studied by Hara (1987), Harris (1994).

Concept of Trading Volume and Liquidity in the Market: Confliction has arisen among researchers as far as the trading volume and liquidity concept is concerned. Due to the difference among the behavior of operators, they choose to negotiate at that time, when there is liquidity in securities (elevated depth and narrow spread). Different studies explored positive relation between trading volume and liquidity as explained by Chordia and Subrahmanyam (2000). There exists an inverse and negative relation between these two items i.e. quoted spread (quoted depth) and trading volume. Contrary results are shown by the studies of Glosten, Lawrence and Milgrom, (1985) supporting that forceful liquidity does not require high volume. Illiquid market will not show a prediction of a symmetrical variation of the ask prices and the bid prices and vice versa. Ask price lower towards the bid price and bid price go up toward ask price.

Evolving Volatility and Liquidity Treatment in the Market: Volatility has shown negative result towards spread as predicted by inventory and asymmetry information model (Goldstein \& Kavajecz, 2000). Bid-ask spread are enlarged as a result of increase in volatility in the market. When loss of unexpected price variation is experienced during the period of strong volatility, then it is the duty of market makers to require high return (enlarged of bid-ask spread) for the compensation of the losses. 
Reaction in different Days of the Season and Liquidity in the Market: "U" curve was observed by Mannaî (1997) in his study as analyzing the behavior of an in trading spread calculated at interval of 30 minutes for 1902 quoted securities on NYSE/AMEX. As American stock markets has been a source of measuring of liquidity. Simultaneously, the studies of Chordia and Subrahmanyam (2000) explored the effects of days of the weak on liquidity. Depth was positively and spread was negatively significant on Tuesday Wednesday and Thursday. Studies found an increase in depth during holidays and also on Friday and decrease in liquidity was experienced and Elevated co-efficient in total value than the remaining week days as far as Tuesday is concerned.

How Pakistan Stock Market is considered with these Concepts: In order to improve the liquidity of Pakistan KSE, SECP has already taken some strong measure to improve the activities at the exchange market and to facilitate the liquidity in the capital market. "BANAMI" transactions have been banned. After the crisis of 2005, severe action was taken by SECP based on transparency and necessity of diffusion of information in real time (Secp, 1997). Similarly, certain enhancement measures regarding liquidity are also taken. This study is based on the domain of market microstructure of KSE. This study is going to explore different measures of liquidity in this emerging market of the south Asia. Due consideration is given to all those factors which measure the quoted stock. Secondary data is available from website of KSE for different securities and stock. Financial intermediaries (workers) and financial analysts are also a source of providing necessary information of daily price, bid ask price, number of shares traded at the bid and ask quoted. Sunday is holiday in Pakistan and Saturday is also a bank holiday and other local holidays also excluded from study as no stock is quoted in these holidays. The study is based on the information from 1990-2014. The study sample is based on the more than 350 securities quoted in KSE.

\section{History of various measures of liquidity in Karachi stock market}

The basic idea of our study is the calculation of different measures of liquidity on the grounds of average data available on weekly basis: the quoted depth (DE), quoted spread (S), the effective spread also called as lambda (SE) and the proportional effective spread (SP) Now it is desirable to explain these Measures of the Liquidity which we used in the form of a formula:

-Quoted Spread: S = Ln (log) (Ask/Bid); (treating "Ask", being the price offered by the seller and Bid, is the price offered by buyer).

-The depth: DP = Ln (Q ask) + Ln (Q bid)

(It is suppose that asked quantity and bided quantity is explaining about the quantity being available with guarantee for the purpose of trading at the quoted price ask quoted price bid)

Now in the second instance, we are looking to check the assumption that:

"All measures of spread are positively correlated with each other across time and negatively correlated with depth". The collective liquidity of the market measures is given Table 1.it is also presenting the variable correlation

Table 1: Correlation

\begin{tabular}{lllll}
\hline & SPM & SM & SEM & DEM \\
\hline SPM & 1 & & & \\
SM & 0.93 & 1 & & \\
SEM & 0.91 & 0.93 & 1 & \\
DEM & -0.12 & -0.19 & -0.33 & 1 \\
\hline
\end{tabular}

As precious studies revealed and we expected, depth (DPEM) is showing negative correlation with all Spread measures. Other than this, it is observed that perfect positive correlations between spread measures. Thus the strength of these measures of liquidity has been proved by the results from data taken from Karachi stock exchange market. 
Relationship between individual liquidity of stock with over all liquidity in the Market Liquidity: First of all, we have to estimate autoregressive model of the proxy of liquidity regarding individual stocks and study; is the outcomes from the autoregressive model are correlating for the different stocks at individual level? According to our expectations, we deduce a correlation which is showing a positive figure for 230 regressions out of 249 regarding each measure of liquidity in KSE. Result compiled shows that the average correlation is to the 0.31 value is for proportional effective spread, 0.23 for Depth, 0.33 for lambda and 0.36 for quoted spread. As it is evident from this result, that it is yielding to the studies explored by Huberman \& Halka (2001) and is a proof of the existence of the ordinary factors of liquidity in Karachi stock market. Conclusively we may associate these ordinary factors to those factors those are in variation with other measures. They include volatility and lag variable of liquidity measure, traded volume, return on securities and number of transaction trade and so many others. Chordia and Subrahmanyam (2000) studied to estimate the simple "market model". As it is observed that the outcomes of the estimate of market model in eq. (4) are strong enough so far as this sample is considered. Results show that, all coefficients have positive value; anyhow $11 \%$ is not only significant. It is proved now that the aggregated market liquidity is sturdy correlated with the individual stock liquidity, which is once again a source of reinforcement for the hypothesis of the authentication of the market model modified to various measures of liquidity in KSE Pakistan. Surprising it is clear that, the descriptive power of previous model is unimportant in KSE. Actually, the coefficients average determination for the variant liquidity measures shown results; $27 \%$ for the effective spread, $17 \%$ for the quoted depth, $32.3 \%$ for the lambda and $30 \%$ for the quoted spread in this study. It is to be assumed that there may be the presence of noise. There may be the existence of other dominating liquidity factors for individual stocks in the Karachi stock market.

Important Studies on Individual Determinants of the Liquidity in the KSE: The empirical literature on market microstructure and the various studies proved the hypothesis that liquidity is directly collateral to the premeditated norms computing market performance. These factors include: number of trades, lag variable of liquidity measure, trading volume, volatility, return and others.

Concept of the Trading volume: It is considered that the ambivalent effect on the spread on the basis of trading volume is experienced under certain conditions. In the language of finance, trading volume is the bus which carries the bulletin that is ignore by the market maker. Under these cases, the enlargement of spread is made by him to hedge his situation in the market. But due to the competition, the situation in the market is against his expectations. So, he could be gratified to decrease spread and change the volume in order to smooth the market. The depth of market and the effects of the trading volume are showing a positive relation as explored in various studies. The estimation of this equation has required us to use of Panel data for 350 stocks quoted in continuous and most active on the KSE on the period going from 1990 to 2015, for each stock. Actually, in this case, a lot of observations have taken for each variable so far.

Table 2: Contributors to the General Variations in Liquidity of the Market

\begin{tabular}{|c|c|c|c|c|c|c|}
\hline \multicolumn{2}{|c|}{ PANEL } & C & $\mathrm{V}$ & $\mathrm{R}$ & $S(-1)$ & $R^{L}$ \\
\hline \multirow[t]{2}{*}{$S$} & & $\begin{array}{l}0.01848 \\
5\end{array}$ & $\begin{array}{l} \\
0.001286\end{array}$ & $\begin{array}{l}- \\
0.025352\end{array}$ & $\begin{array}{l}0.26479 \\
8\end{array}$ & \multirow[t]{2}{*}{$\begin{array}{l}0.13108 \\
3\end{array}$} \\
\hline & $\mid t-c a l$ & $(5.402999)^{*}$ & $(-4.121660)$ & $(-0.661348)$ & (5.506235) & \\
\hline \multirow[t]{2}{*}{$S P$} & & $\begin{array}{l}0.00576 \\
6\end{array}$ & $\begin{array}{l} \\
0.000442\end{array}$ & $\begin{array}{l}-0773348 \\
0.078\end{array}$ & $\begin{array}{l}0.33925 \\
4\end{array}$ & \multirow[t]{2}{*}{$\begin{array}{l}0.22140 \\
6\end{array}$} \\
\hline & $t$-cal & $(7.193580)^{*}$ & $(-3.7816875)$ & $(-3.73234)$ & (7.509629) & \\
\hline \multirow[t]{2}{*}{$D E$} & & $\begin{array}{l}2.81218 \\
9\end{array}$ & $\begin{array}{l}- \\
0.046168\end{array}$ & $\begin{array}{l}31.0519 \\
0\end{array}$ & $\begin{array}{l}0.50876 \\
9\end{array}$ & \multirow[t]{2}{*}{$\begin{array}{l}0.32113 \\
4\end{array}$} \\
\hline & $t$-cal & $(3.306671)^{*}$ & $(-1.142465)$ & (5.6942387) & $(12.99661)$ & \\
\hline \multirow[t]{2}{*}{$S E$} & & $\begin{array}{l}0.00156 \\
9\end{array}$ & $\begin{array}{l}- \\
0.000147\end{array}$ & $\begin{array}{l}- \\
0.010645\end{array}$ & $\begin{array}{l}0.38751 \\
9\end{array}$ & \multirow[t]{2}{*}{$\begin{array}{l}0.27179 \\
1\end{array}$} \\
\hline & $\mid t$-cal & $(5.102276)^{*}$ & $(-4.926551)$ & $(-2.091210)$ & $(8.519462)$ & \\
\hline
\end{tabular}


- Explanation of trading volume: Results regarding the trading volume is evidencing a significantly negative association for the distinct measures of illiquidity in the Table. At the same time, the relationship of depth is showing inverse association with trading stock volume. This is an insignificant association (showing t-calculated -1.14).

- Explanation of Return: There is significant negative association between Return and the quoted \& listed spread (showing t-calculated -0.661348); similar result are shown by above table towards "lambda" (shown t-calculated -2.09) and also for proportional effective spread (showing t-calculated -3.73). Apart from this, return is significantly positive association to quoted depth (t-calculated 5.69) in this study on KSE.

- Explanation of Past information revealed: As indicated by Tables 2 that, even if various measure so counted for the variable return, volume, the previous revealed information remains a tactical variable that adds intensely \& meaningfully. It is used fruitfully for the explanation of the behaviour of the diverse measures of liquidity of various stocks in KSE.

Contradiction is shown by our results regarding this assumption that return and the traded volume backing sharply in the liquidity explanation in the KSE. It is concluded then; return and the volume of the traded stock has nothing to do with the with variant measures of the liquidity. And they don't establish a shared aspect for the diverse measures of the liquidity of the securities listed in constantly in KSE. On the other hand it may be considered, probably, that the past information so revealed in the market serve as a important contributor regarding the diverse measures of liquidity for total listed stock in incessant in KSE.

\section{Conclusion}

Financial Literature is rich with different studies which reveal that market microstructure is exploring a variety of liquidity measures, such as: lambda, proportional effective spread, the quoted spread, quoted depth \&many others as liquidity determinants. In order to verify this fact \& legitimacy of the measures in the Pakistani stock exchange market. Testing of the assumption of variation inversely proportionality of variant measure of illiquidity to the quoted depth in this market. These measures of illiquidity are proportional effective spread, quoted spread and lambda. Last hypothesis was reinforced as the sample of 350 company's quoted stock was continuously traded. As it is mentioned that the individual stocks and the total stock of all the market in Pakistan. The main purpose of the study is to check through research the assumption whether variable explained are actually existing in the Karachi stock and capital market. All these variables are swaying listed liquid stocks in nonstop in the Karachi stock market. Surprising observed outcomes are shown by our study in this regard and they are as follows:

Finally it is proved that there exists a "market model" for liquidity in Pakistan stock market. In this study trading volume is showing significantly positive association with the liquidity of the stocks in Pakistan stock market. There is ambiguity regarding the effect of the quantity of traded volume on liquidity of the stocks. Another important fact is revealing that with liquidity of stocks is showing a significantly positive association with return in this Pakistani stock market. In our market insignificant relationship is shown between liquidity and the volatility. In this study of Pakistani market, liquidity is auto-regressive of order 1. Hence it is revealed that the current liquidity scenario is best explained by the lagged liquidity in the market. It is necessary to believe that the past revealed evidences and the data in the form of different information is also one of the important contributor for the explanation of diverse measures of liquidity for all stocks regarding Pakistani stock market.

\section{References}

Admati, A. R. \& Pfleiderer, P. (1988). A Theory of Intraday Trading Patterns. Review of Financial Studies, 1, 340.

Amihud, M. (1986). Liquidity and stock return. Financial Analysts Journal, (42), 43-48.

Amihud, M. (1989). The effects of beta, bid-ask spread, residual risk on stock returns. Financial Analysts Journal, (42), 479-486.

Ananth, M. (2000). Market Microstructure: A survey. Marshall School of business. University of southern California Los Angelos, CA 90089-1427, (213)-740 6519. Marsh 16, 2000. 
Annaïch, G. (2001). Impact des transactions d'initiés sur la liquidité. Banque \& Marchés, 53, 22-33. Juillet-Août 2001.

Bagehot (1971). The only game in town. Financial Analysts Journal, 27, 12-14.

Bellalah, M. \& Simon, Y. (1999). Options, contrats à terme et gestion des risques. Collection Gestion, Economica, 14(15).

Black, K. (1971). Toward a fully automated stock exchange. Financial Analysts Journal, 27, 28-35.

Brennan, S. (1996). Market microstructure and asset pricing on the compensation for illiquidity in stock returns. Journal of financial economics, 41(6).

Chordia, R. \& Subrahmanyam, L. (2000). Commonality in liquidity. Journal of financial economics, 56(2).

Clyman, J. (1998). Liquidity without volume. Journal of Futures Markets, (18), 281-296.

Copeland, G. (1983). Information effects on the bid-ask spread. Journal of Finance, 38, 1457-1469.

Demsetz, H. (1968). The cost of transacting. Quarterly Journal of Finance, 45, 33-53.

Frino, H. (2006). The impact of electronic trading on liquidity. Finance discipline, School of Business, University of Sydney, NSW, 2006.

Glosten, L. R. \& Milgrom, P. (1985) Bid, ask, And Transaction Prices in a Specialist Market with Heterogeneously Informed Agents. Journal of Financial Economics, 14, 71-100.

Goldstein, K. \& Kavajecz, L. (2000). Eighths, sixteenths and market depth: changes in tick size and liquidity provision on the NYSE. Journal of financial economics, 56, 125-149.

Huberman, G. \& Halka, D. (2001). Systematic Liquidity. The journal of financial research, 24(2).

Harris, T. (1994). Minimum price variation, discrete bid-ask spread and quotation sizes. Review of Financial Studies, 7, 149-178.

Hasbrouck, J. (1993). Assessing the quality of the securities market: A new approach to transaction cost measurement. Review of financial studies, 6, 191-212.

Ho, S. (1981). Optimal dealer pricing under transactions and return uncertainty. Journal of Financial Economics, 9, 99-117.

Keynes, J. M. (1930). Treatise on money. Macmillan, London.

Khan, F., Muneer, S. \& Anuar, M. A. (2013). Relationship between stock prices and economic variables: Sectoral analysis. Actual Problems of Economics, 143(5), 544-553

Kyle, A. (1985). Continuous Auctions and Insider Trading. Econometrica, 53, 1315-1335.

Mannaî, S. (1997). De la microstructure des marchés en général à la liquidité en particulier. Edition Economica.

Muneer, S., Butt, B. Z. \& Rehman, K. U. (2011). A Multifactor Model of Banking Industry Stock Returns: An Emerging Market Perspective. Information Management and Business Review, 2(6), 267-275.

O'Hara, P. (1987). The microstructure of the market making. Journal of Financial and Quantitative Analysis, 21, 361-376.

Paul, I. \& Benston, G. (2000). Liquidity Beyond the Inside Spread: Measuring and using information in the limit order book. Goizueto Business school, Emory University, Atlanta, GA, 30322. July,2000.

Robert, F. E. \& Lange, J. (1997). Measuring, forecasting and explaining time varying liquidity in the stock market. University of California San Diego, May 1997. 